\title{
Projecting animal economies of scarcity: on Racing Extinction
}

\author{
Andy Hageman ${ }^{1} \cdot$ Rachel F. Brummel $^{1}$
}

Published online: 25 June 2016

(C) AESS 2016

Racing Extinction is a visually captivating environmental documentary that sets out to explore the global context for mass extinction in the modern era. The film is director Louie Psihoyos's follow-up to his Oscar-winning The Cove (2009) and draws upon familiar methods - cinematic, narrative, and structural - to weave a simultaneously devastating and hopeful exploration of the loss and conservation of biodiversity on Earth. Psihoyos combines visual storytelling with his own brand of environmental activism, moving between backroom dealings in the illegal wildlife trade, innovative imagery depicting marine wildlife and unseen elements of climate change, and the streets of New York City where the film culminates in a city-wide public art demonstration. The following review begins with some critical analysis of the film's key elements and then pivots into potential pedagogical approaches to Racing Extinction in environmental studies courses.

Suggestively, some of the most engaging strengths of Racing Extinction also serve as points for analyzing the ecological ideologies, overt and latent, at work in the film. In particular, the film contains fundamental ideological contradictions concerning its use of aesthetic discourse on natural beauty, its presentation of activists, and its celebration of the power of media to inform and inspire. To begin, take the rapturously gorgeous ocean and forest visual footage that dominates the early half of the film but that is consistently threaded throughout. Scene after scene, sequence after sequence, Racing Extinction provides viewers glimpses of

Rachel F. Brummel

brumra02@luther.edu

1 Luther College, Decorah, IA 52101, USA places on the planet many people never experience firsthand. And the masterful cinematography and editing makes these captivating. We see whales and dolphins, alone and in groups, at times comingling with human beings in the water. We see manta rays and sharks moving gracefully. In the realm of wildlife films, Racing Extinction presents some of the highest quality visuals to date. Such scenes are frequently paired with voice-over narration by Louie Psihoyos or the featured scientists and activists, and their remarks often invoke beauty and the aesthetic dimension to describe their encounters with the non-human beings on screen as well as their environs. As such, one of the primary arguments the film makes to persuade viewers to care about mass extinction and take action to ameliorate it is for the sake of the beauty, the aesthetic qualities, of the non-human species that are in peril.

On the one hand, beauty can be a significant motivator. The appeal to maintaining a world of creature comrades that inspire awe and wonder in us human beings is strong, it connects with a long tradition of nature painting, writing, and other arts. On the other hand, though, this discourse, verbal and visual, of beauty as compulsion to care runs the risk of reinforcing an imaginary distance between human beings and the so-called rest of the world. One of the very first spoken lines of the film refers not to the land or, even better, to the ecosystem(s) on visual display at that moment, but to the landscape. The discourse of beauty can readily transform complex biophysical systems into commodities for aesthetic consumption - to really cool stuff that decorates our place. Then, the ecological thought and ethic becomes a version of "This is why we can't have nice things!" This particular slippery slope is observable in the way Racing Extinction privileges non-human beings that slot easily into ready-made notions of natural beauty. Put simply, the beauty discourse reveals a deep ideological structure at the core of the film-a critical analytical point that can be leveraged as a powerful 
teaching element rather than as a problematic that would lead anyone to dismiss the film.

To pivot from the discourse of beauty to depiction of activists, Racing Extinction resonates strongly with Psihoyos's previous film, The Cove, as they both feature heist-genre style team-building sequence whereby individuals with particular sets of skills join forces to document criminal actions against non-human beings. In The Cove this worked particularly well because the team had a rather singular focus; in Racing Extinction, these gestures feel fragmented - as does the film on the whole - because the film shifts seemingly haphazardly across geographic locations and non-human species. On the positive side, all the activists in Racing Extinction exhibit deep commitment, often as a result of their journey to learn more about species in danger. Student viewers may well be inspired by these models of action as the combination of learning more and acting on the knowledge acquired. In that sense, Racing Extinction balances an overwhelming, depressing subject with the prospect of doing something to help. That said, the activists featured tend to exist at the upper echelon of the socioeconomic continuum. Their conversion narratives represent activism emerging from positions of wealth and privilege, thereby excluding models of activism from middle and lower class people. As a result, the forms of hope Racing Extinction offer simultaneously redeem the class that has traditionally capitalized on the economic activities that drive mass extinction and reinforce the notion of the marketplace as the hall of democracy for voting change with dollars. At no point does Racing Extinction consider the sustainability of the capitalist marketplace as it stands. Rather, the film merely suggests that people stop harvesting manta rays to sell their gills in order to sell tourist experiences of swimming with the manta rays to people with the wealth and leisure to afford such luxuries - no questions about how the wealth to sustain this new market might continue driving extinction amongst other ecological crises and catastrophes. The emphasis of simply shifting consumer choices in the market as it stands comes through clearly as Racing Extinction intercuts clips from PSA ads the former NBA star Yao Ming amongst the team's sting-operations on shark fin dealers, ultimately including a statistic about the decline of shark fin consumption in China following that campaign. Not only does this quick stat trade upon a presumed causation behind the correlation but it also leaves the structure of consumption in tact.

Finally, the film concludes with a sustained piece on public performance art, principally that of projecting video on buildings, walls, clouds, etc. This salvo on spectacle gets the people in the film excited about the power of media to inform and inspire, and student viewers will doubtless be inspired too. Psihoyos's modus operandi of depicting environmental activism at the edge of legality - of civil disobedience - is in full force as we see police stopping one of the projector cars, seemingly serving the interests of petroleum companies as opposed to activist citizens. On the positive side, this last portion of the film opens productive space for thinking about how to represent an ecological crisis of such vast proportions. Ecological scales are almost unimaginably massive-just think about how Darwin's Natural Selection required a revolution in the idea of temporality. And yet, when you pay close attention to this performance art sequence, you notice a lot of people are filming the spectacle on their mobile devicesadding yet one more layer of aesthetic distance from the already very mediated one of the projected film. Thus, the celebratory ideology of the power of media spectacle that Racing Extinction promotes overtly is haunted by the implicit ideology of enjoying the act of human inscription everywhere, on everything. Inadvertently, this media-fest provides a very apt representation of the Anthropocene- the epoch of human traces inscribed everywhere on the planet.

With an eye toward pedagogical value, Racing Extinction excels in allowing students to see unseen elements of biodiversity loss and extinction. Psihoyos and his team reveal the murky networks of illegal wildlife trade through tracking, for example, manta ray hunting in coastal villages in Indonesia to temporary markets in China, where piles of freeze-dried manta gills provide a startling visual into processes of living bodies being carved up for commodification. Students will gain an appreciation for some of the social and economic complexity underlying endangered species supply and demand chains. Once again, however, the true strength of this documentary is in the innovative visual imagery that works to reorient our view of the non-human in the environment. Psihoyos gives standing to oxygen-producing microscopic plankton declining precipitously in the ocean due to climate change. Through visualizing the unanswered call of the last remaining (and now extinct) Hawaiian O'o bird to a mate that is not there, we are able to clearly see absence and loss. Some of the most striking work in the documentary visualizes the greenhouse gases which invisibly saturate our atmosphere, as well as our conversations about climate change. Psihoyos makes visible carbon dioxide emissions from rush hour traffic and coal-fired power plants through a video $\mathrm{CO}_{2}$ filter, thus making an argument for the ways the invisible is easily ignored. At its core, Racing Extinction provides students traction in understanding the slippery issue of extinction, which is often spatially and temporally displaced from students' lived-experience.

Racing Extinction also touches on several critical concepts for academic understandings of biodiversity loss and extinction. Though the treatment of some of these concepts - a very brief bit on the concept of the Anthropocene, for exampleremain rather superficial, viewing the documentary nonetheless provides an opportunity for educators to connect to class conversations and give additional salience to course content. 
The film features prominent scientists discussing concepts such as background and modern extinction rates, placing the proposed Holocene extinction - or sixth extinction - in context with previous mass extinctions in geologic history. The documentary also addresses contemporary scientific understanding of issues such as ocean acidification, links between climate change and biodiversity loss, and institutional responses to wildlife trade with a focus on CITES (Convention on International Trade of Endangered Species) and would thus be particularly useful for introductory courses that address mass extinction, conservation, and environmental change.

Substantively, Racing Extinction somewhat overstates its own scope in presenting itself as a comprehensive look at mass extinction in the Anthropocene. The film does a better job of examining the illegal wildlife trade in marine animals in Asia than presenting a complex treatment of global biodiversity loss. While the active investigation of the illegal wildlife trade by the Racing Extinction team is no doubt a compelling storyline, its orientation as the central thread of the documentary has the effect of elevating the importance of the traditional Chinese medicine as a driver of biodiversity loss relative to greater forces such as habitat loss and invasive species. Psihoyos does good work in presenting climate change as a contemporary cause of extinction, but the film struggles to connect the unfolding Asian wildlife trade story with these broader conversations. The film does distinguish between direct and indirect drivers of biodiversity loss, leaving educators the opportunity to expand upon the complexity, interconnectedness, and relative importance of drivers through class conversations.

To connect to a point in the analytical section above, Psihoyos does scaffold environmental activism into the fabric of the documentary, which will resonate with students seeking self-efficacy. We see film-makers and environmental leaders such as Jane Goodall grapple with relationships between apathy, hope, and action, humanizing the process of environmental change in a way that will be appealing and accessible to students. However, this focus on environmental change as coming through the work of high-capacity, highly-resourced individuals such as the Racing Extinction team and Tesla Motors CEO Elon Musk risks perpetuating a developed world elitism that celebrates technological and capitalistic responses to biodiversity loss and climate change. Additionally, the documentary underemphasizes the importance structural drivers of biodiversity loss and institutional-level opportunities for change. For example, the film presents the issue of agriculturally associated habitat loss and climate change as a problem best solved by cutting meat out of one meal a week rather than, for example, addressing broader political and economic structures that incentivize deforestation for agriculture in places like Brazil. While this message is an understandable strategy to change behaviors of individuals viewing a documentary, it understates issues of politics and power, institutions, and multi-level change that educators would want to consider in their classrooms.

Moreover, Racing Extinction misses some opportunities to delve more deeply into the social complexity that facilitates biodiversity loss, poverty, and conservation. In particular, moments in the documentary reinforce problematic relationships of power and privilege in the ways that actors in the Global North envision conservation might occur in the Global South. In one illustrative scene, film-makers return to the Indonesian village where they previously filmed local fishermen hunting manta rays to be trafficked to China. During this first trip, fishermen discussed the persistent poverty they experience and their struggle to support their families without the income from manta rays. In the second visit, members of the Racing Extinction team had successfully advocated for amendments to an international treaty that banned the hunting and trade of mantas. During this visit, team-members present themselves as helping to solve this problem, all the while unpacking a large blow-up manta ray and boxes of expensive video projection equipment to show a film that presents their vision for a transition to a tourist-based economy for the village. Racing Extinction seems to endorse this intra-cinematic gesture as an appropriate way to begin the challenging cultural and economic transition and undercuts the complexity of the issues at play. This type of scene threatens to reinforce a paternalistic view of conservation as colonialism that those in the conservation community have worked to challenge and of which students should be skeptical.

By way of a summary, Racing Extinction is a pedagogically worthwhile environmental documentary that tells a visually stunning story about biodiversity decline, while presenting a vision for positive change. The film's shortcomings provide opportunity for educators to encourage critical reflection on dominant ecological ideologies that frame the documentary. The film would work well in a course to introduce a range of species and ideas related to mass extinction, and, at an advanced level, it would serve as a text for rigorous critique of ecological ideologies and ethics. Psihoyos's personal reflections as a photographer and film-maker, along with the largescale public art projection that closes the documentary, also would provide fodder for discussions concerning the role of art as environmental activism. Racing Extinction seems less apt for a course focusing on cinema and/or media studies as there are other eco-documentaries that surpass it in terms of narrative, structure, and cinematography. If one chooses to teach this film, it might be productively paired with selections from some of the classic works on wildlife film (Derek Bouse's Wildlife Films, Cynthia Chris's Watching Wildlife, or Greg Mittman's Reel Nature) or, for a more theoretical course, with Akira Mizuta Lippit's highly insightful book Electric Animal. 